\title{
Using Basic Science to Design a Clinical Trial: Baseline Characteristics of Women Enrolled in the Kronos Early Estrogen Prevention Study (KEEPS)
}

\author{
V. M. Miller • D. M. Black • E. A. Brinton • \\ M. J. Budoff • M. I. Cedars • H. N. Hodis • R. A. Lobo • \\ J. E. Manson • G. R. Merriam • F. Naftolin • \\ N. Santoro • H. S. Taylor • S. M. Harman
}

Received: 6 March 2009 / Accepted: 27 April 2009 /Published online: 22 May 2009

(C) The Author(s) 2009. This article is published with open access at Springerlink.com

\begin{abstract}
Observational and epidemiological studies suggest that menopausal hormone therapy (MHT) reduces cardiovascular disease (CVD) risk. However, results from prospective trials showed neutral or adverse effects most likely due to differences in participant demographics, such as age, timing of initiation of treatment, and preexisting cardiovascular disease, which reflected in part the lack of basic science information on mechanisms of action of hormones on the vasculature at the time clinical trials were designed. The Kronos Early Estrogen Replacement Study (KEEPS) is a prospective, randomized, controlled trial designed, using findings from basic science studies, to test
\end{abstract}

\footnotetext{
V. M. Miller $(\varangle)$

Medical Science 4-62, College of Medicine, Mayo Clinic,

200 First St. SW, Rochester, MN 55905, USA

e-mail: miller.virginia@mayo.edu

D. M. Black • M. I. Cedars

School of Medicine, University of California,

San Francisco, CA, USA

E. A. Brinton

School of Medicine, University of Utah,

Salt Lake City, UT, USA

M. J. Budoff

Los Angeles Biomedical Research Institute at Harbor-UCLA,

Torrance, CA, USA

H. N. Hodis

Atherosclerosis Research Unit, University of Southern California,

Los Angeles, CA, USA

R. A. Lobo

College of Physicians and Surgeons, Columbia University,

New York, NY, USA

the hypothesis that MHT when initiated early in menopause reduces progression of atherosclerosis. KEEPS participants are younger, healthier, and within 3 years of menopause thus matching more closely demographics of women in prior observational and epidemiological studies than women in the Women's Health Initiative hormone trials. KEEPS will provide information relevant to the critical timing hypothesis for MHT use in reducing risk for CVD.

Keywords Menopause $\cdot$ Hormone Treatment . Conjugated Equine Estrogen · Women's Health Initiative · Timing Hypothesis

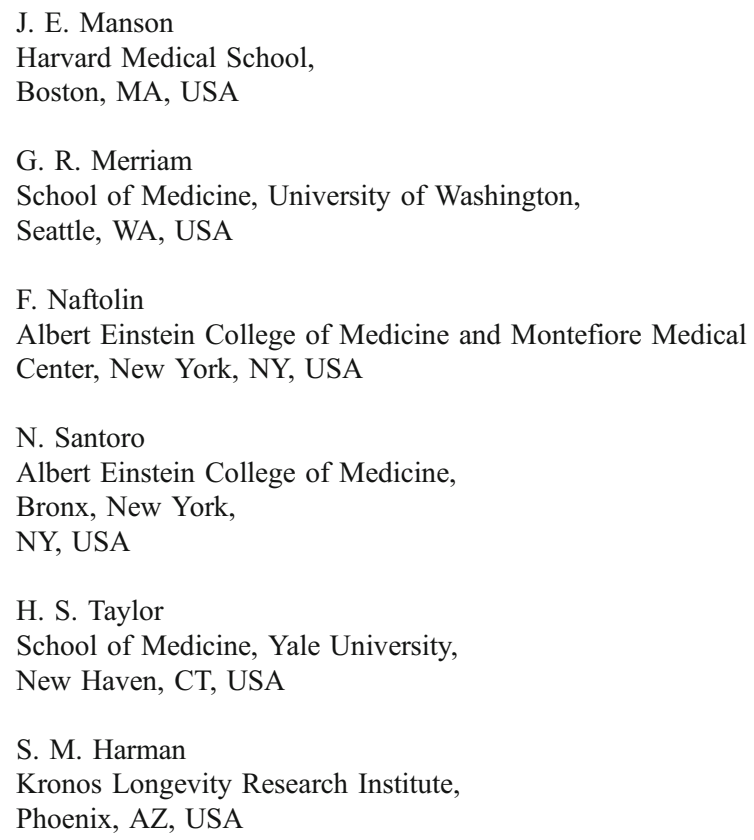




\section{Introduction}

Chronic diseases potentially affected by menopausal hormone treatment (MHT) include cardiovascular disease (CVD; which includes all atherosclerotic disease such as coronary heart disease (CHD) and stroke), osteoporosis, venous thromboembolic disease and cancers of the breast, endometrium, and colon. These diseases constitute the most common sources of morbidity and mortality among women and cost scores of billions of dollars annually. Of these, CVD remains the single greatest killer of women, accounting for approximately $40 \%$ of total mortality vs. about $5 \%$ for breast cancer [62]. Over the last decade, controversies regarding benefits, risks, and appropriate use of MHT to prevent cardiovascular disease have flared when emerging clinical trial evidence appeared to be at odds with wellestablished observational and epidemiological data. This paper provides a brief review of the historical perspective behind the controversy surrounding the use and efficacy of MHT for prevention of CVD and highlights the design and demographics of an ongoing clinical trial designed to help resolve this controversy, in particular, as to the timing relative to menopause for initiation of treatment (critical timing hypothesis).

\section{Historical Considerations}

Human Studies Over the past 30 years, numerous large observational studies $[9,10,24,32,34,37,84,97]$ found that MHT, in addition to reducing menopausal symptoms, reduced both CVD incidence and all-cause mortality by nearly one half in postmenopausal women. Furthermore, MHT was reported in both observational studies and randomized clinical trials to significantly reduce the risk of osteoporosis-related fractures [12, 23, 65] and colon cancer [27] while increasing age-adjusted incidence of breast cancer by about $20 \%[6,17,76]$, but decreasing breast cancer mortality by over $20 \%$ [34]. Based on the expectation of CVD protection, the benefit/risk ratio for MHT was calculated to be positive for most women [16].

The biological plausibility of atheroprevention by MHT is supported by a body of investigations demonstrating that estrogens improve a variety of known and suspected risk factors for atherosclerosis [44]. The Postmenopausal Estrogen/Progestin Interventions (PEPI) prospective trial, which compared the use of conjugated equine estrogen (CEE) alone and in three different CEE-progestin combinations and placebo in 875 healthy postmenopausal women aged 45-64 years, showed increases in high-density lipoprotein cholesterol (HDL-C) and decreases in low-density lipoprotein cholesterol (LDL-C) and fibrinogen in women receiving estrogen [91]. Subsequently, other studies have confirmed favorable lipid effects, including lowering of LDL-C and lipoprotein-a and raising of HDL-C levels [19, 28, 39, 53, 82].

Estrogenic effects on lipid profiles alone, however, were considered unlikely to account for all of the evident beneficial effects of estrogen which appeared to account both for lower atherosclerosis rates in premenopausal women vs. age-matched men and for the exponential increase in cardiovascular risk in women associated with the menopause-related decline in estrogen. However, in the early 1990s when some of the results of these epidemiological and observational studies were published, little was known about potential nonlipid actions of estrogen on the cardiovascular system.

However, recommendations were emerging from the observational studies and the PEPI trial for the use of MHT for women with coronary heart disease or at high risk for coronary heart disease [29]. Following on the heels of these recommendations, a major prospective clinical trial, the Women's Health Initiative (WHI), was designed in 1991 and initiated in 1992 to test whether MHT would provide primary prevention for cardiovascular disease (i.e., reduction in the number of major cardiovascular events, heart attacks, and strokes). The selection of hormonal treatments (type and dose) for use in the WHI was based on the MHT regimens reported most frequently prescribed in the USA and which had been used in previous observational studies and the PEPI trial: conjugated equine estrogen $(0.625 \mathrm{mg} /$ day) plus medroxyprogesterone acetate (MPA; $2.5 \mathrm{mg} /$ day), or CEE alone in women without a uterus [35, 91].

In order to have sufficient statistical power to detect significant differences in cardiovascular event rates within the relatively short time frame of the trial, women across a wide spectrum of ages from 50 to 79 years with the vast majority of subjects older than 60 years were enrolled. In addition, a secondary end point in WHI was bone density for which there were few data available on effects of MHT in older women. In order to minimize dropouts among subjects randomized to placebo, women with severe menopausal symptoms who could not tolerate a 3-month washout period or might not tolerate randomization to placebo were excluded. Thus, for reasons of study practicality and statistical power, very few WHI subjects were like the women in the observational studies because observational data are based on clinical practice and in typical clinical practice, MHT was initiated early in the course of estrogen deficiency usually to treat menopausal symptoms. Occasionally, MHT was initiated years after the menopause. Women also were excluded from the WHI for prior CVD events but only by self-report. While these criteria were believed to be sufficient at the time of the trial, many subjects had significant CVD risk and/or were found to have had a prior CVD $[35,71]$. 
The CEE+MPA portion of the WHI trial was stopped early in 2002 because accumulating data showed a trend toward increased breast cancer which crossed a prespecified stopping point; thus, the benefit/risk ratio for the treatment was believed to have shifted from positive to negative [71]. Ironically, the effect on breast cancer was later found not to be statistically significant, and early termination of the trial rendered other findings similarly inconclusive. The CEE alone portion of the WHI was also terminated early, although this time for perceived lack of likelihood of ultimate net benefit, again truncating data collection and confounding interpretation of results. The key question remaining to be answered is "What are the reasons for the discrepancies in effects on cardiovascular protection among observational studies and this major clinical trial?"

Animal Studies Clues to the answer to this question come as a result of initiatives in the early 1990s from the National Institutes of Health that encouraged research into basic mechanisms of estrogen actions. The typical experimental animal model used to investigate arterial actions of estrogen was to remove ovaries from healthy adult animals. Following ovariectomy, estrogen, usually $17 \beta$-estradiol, was administered immediately or shortly after the procedure by way of intramuscular injection or subcutaneous time-release pellets or infusion minipumps. Thus, the timing of treatment was similar to that of clinical practice, that is, to initiate treatment around the time of estrogen deficiency.

In support of this concept, estrogen treatment consistently reduced by $50-70 \%$ histologically defined coronary artery atherosclerosis if treatment was initiated immediately after ovariectomy in surgically menopausal (ovariectomized) cynomolgus monkeys, which develop atheromatous lesions similar to those in humans, but not if treatment was delayed for 2 years [14].

In brief, these studies provided evidence to support potentially beneficial arterial actions of estrogen, as was suggested by observational studies in humans, including reduced formation of atheroma lesions at sites of endothelial injury, reduced blood pressure, and increased arterial compliance, all actions which maintain arterial health. Conversely, the absence of estrogen and/or related downregulation of estrogen receptors accelerates development of atherosclerosis [1, 15, 52, 86-89, 92, 93, 95, 98].

\section{Rationale for the Design of the Kronos Early Estrogen Prevention Study}

Thus, what has emerged from results of studies conducted in experimental animals and what can be identified as a critical difference between previous observational studies in humans and the WHI hormone trials was the time for initiation of treatment relative to menopause [43]. In particular, the mean age of menopause in the USA is 51 years, which corresponds to the age of women in the Nurses Health Study (NHS) who initiated MHT as in usual clinical practice for menopausal symptoms in the perimenopause [31]. This age and timing of MHT initiation contrasts with that of participants in the WHI who were an average of 63 years of age at MHT initiation, approximately 12 years past menopause [46, 59]. Because atherosclerosis progresses gradually before declaring itself with a clinical event $[60,64]$, a significant number of women in the WHI likely had subclinical atherosclerosis at randomization.

The presence of subclinical disease might have accounted for the tendency for CVD events to be increased early in the WHI, just as in the major secondary CVD prevention study of MHT, the Heart and Estrogen/Progestin Replacement Study (HERS) which began concurrently with the WHI. The HERS showed that in women with preexisting disease, there was an increase in CVD events in the first year or two of the trial. Although continued use of MHT in HERS was associated with a reversal of this trend, the major conclusion from that trial, contrary to conclusions drawn from meta-analyses of the literature [29] was that women with preexisting CHD were not candidates for preventive therapy with MHT [47]. This conclusion changed clinical practice.

Analysis of the NHS and post hoc analysis of data from the WHI based on timing of initiation of treatment relative to menopause supports the concept that initiation of treatment (up to 10 years after the menopause) reduces risk of adverse cardiac events [33, 46, 59]. Furthermore, as in the animal studies, MHT administered to individuals with established atherosclerosis did not induce regression of established lesions [11, 38, 42, 47]. Collectively, these studies suggest that MHT may provide primary prevention for CVD in women by preventing or reducing (slowing) early stages of atherogenic disease processes in the immediate time of menopause when endogenous estrogen shows the steepest decline [43]. Studies in humans, of course, were disadvantaged by the inability to obtain accurate histological assessment of disease progression, and noninvasive techniques to monitor progression of the atherosclerosis, such as B-mode ultrasound imaging of carotid artery wall thickness and plaque or computer-based tomography of coronary artery calcification, were not widely available nor were they sufficiently validated in 1991 to be used as endpoints when the WHI was designed. Advances in these technologies [30, 40] have prompted their use in a small subgroup of the CEE only group of the WHI at the end of the trial [58] and as the major endpoints in ongoing trials of MHT (see below).

An important difference between studies conducted in laboratory animals and clinical trials in humans is that most 
studies in animals, especially rodents, did not administer CEE but rather $17 \beta$-estradiol by a nonoral route. Therefore, possible differences between efficacy and safety of complex conjugated estrogen preparations and transdermal preparations of MHT on cardiovascular parameters remain to be clarified [22, 66, 74, 75, 77].

From these historical considerations, two hypotheses emerge which require rigorous testing in humans: (1) MHT initiated early after menopause (i.e., prior to the appearance of advanced atherosclerotic lesions) will prevent progression of atherosclerosis and (2) oral CEE and transdermal $17 \beta$-estradiol will be similarly efficacious in their arterial effects. These hypotheses are the basis of the Kronos Early Estrogen Prevention Study (KEEPS). Findings of the KEEPS have the potential to affect the health of many millions of women who may endure cardiac events and bone fractures that could be prevented. If there proves to be a window of time in the early postmenopause when initiation of long-term MHT has a net beneficial effect, then women can feel reassured that treatment of their menopausal symptoms when they are likely to be the most severe, can concurrently protect their vascular system, and can reduce bone resorption.

\section{KEEPS Methods}

KEEPS was designed as a randomized, placebo-controlled, double-blinded, prospective trial (KEEPS; NCT000154180) to evaluate effects of MHT on progression of atherosclerosis as defined by carotid intima-media thickness (CIMT) [44] and coronary arterial calcification (CAC) $[8,73]$ in women who more closely match the age of initiation of MHT reported by prior observational studies. Women meeting inclusion criteria subsequently were randomized to daily placebo, oral CEE, or transdermal $17 \beta$-estradiol with placebo or pulsed progesterone for 12 days/month. The detailed inclusion and exclusion criteria for KEEPS have been published elsewhere [36]. In brief, women between the ages of 42 and 58 years of age who were at least 6 months and no more than 36 months from their last menses with plasma follicle-stimulating hormone (FSH) level $\geq 35 \mathrm{ng} / \mathrm{mL}$ and $/$ or $E_{2}$ levels $<40 \mathrm{pg} / \mathrm{mL}$ were eligible. A history of clinical CVD including myocardial infarction, angina, congestive heart failure, or thromboembolic disease excluded women from KEEPS. Other major cardiovascular risk factors excluding participation were current heavy smoking (more than ten cigarettes/day by self-report), morbid obesity [body mass index (BMI) $>35 \mathrm{~mm}^{2} / \mathrm{kg}$ ], dyslipidemia (LDL cholesterol $>190 \mathrm{mg} / \mathrm{dL}$ ), hypertriglyceridemia (triglycerides $>400 \mathrm{mg} / \mathrm{dL}$ ), and uncontrolled hypertension (systolic blood pressure $>150 \mathrm{~mm} \mathrm{Hg}$ and/or diastolic blood pressure $>95 \mathrm{~mm} \mathrm{Hg}$ ) and glucose
$>126 \mathrm{mg} / \mathrm{dL}$. Complete blood count and chemistry panel, estradiol, and FSH were performed at the clinical laboratories at each recruiting center. Lipid profiles and thyroidstimulating hormone (TSH) were performed at the Kronos Science Laboratories (Phoenix, AZ, USA). At screening, women were asked to rank their menopausal symptoms (hotflashes, night sweats, vaginal dryness, dyspareunia, palpitations, insomnia, depression, mood swings, and irritability) as either none, mild, moderate, or severe. Finally, all subjects were screened for CAC and women with Agatston score $\geq 50 \mathrm{U}$, indicating significant subclinical coronary artery disease, were excluded. All women meeting inclusion criteria underwent baseline measurements of CIMT by B-mode ultrasound [44]. All imaging results are read centrally by individuals blinded to participant demographics (CAC at the Los Angeles Biomedical Research Institute at Harbor-UCLA, Torrance, CA, USA under the direction of Dr. M. Budoff and CIMT at the Atherosclerosis Research Unit Core Imaging and Reading Center, University of Southern California, Los Angeles, CA, USA under the direction of Dr. H. Hodis).

Analysis of variance was used to determine statistical significance except where an alternative test is specified. Statistical significance was accepted at $P<0.05$.

\section{Recruitment and Enrollment into KEEPS}

Subjects were recruited through nine clinical study centers (Brigham and Women's Hospital, Boston, MA, USA; Columbia University College of Physicians and Surgeons, New York, NY, USA; Mayo Clinic, Rochester, MN, USA; Montefiore Medical Center, Bronx, NY, USA; Kronos Longevity Research Institute, Phoenix, AZ, USA; University of California at San Francisco, San Francisco, CA, USA; University of Utah School of Medicine, Salt Lake City, UT, USA; University of Washington School of Medicine; Tacoma, WA, USA; Yale University School of Medicine, New Haven, CT, USA) beginning in July, 2005 with complete enrollment of 728 participants qualified for randomization in June, 2008. Subjects were recruited using a variety of strategies including mass mailings, recruiting posters in hospitals and clinics, print and electronic media advertisements, and an internet web page (www. keepstudy.org).

Contacts were asked a series of standard questions from a Phone Screen Interview Form. Of 4,533 phone enquiries, 2,528 callers were disqualified and 927 others, who were qualified, either failed to make or show up for screening visit appointments or did not complete screening for personal reasons. Women who qualified by phone screen gave written informed consent at their screening visit. Of these 1,078 women, 290 candidates were excluded based 
on history, physical examination, laboratory tests, or imaging procedures (Table 1). Some subjects had more than one disqualification factor (45 with two, seven with three, and three with four exclusions). The major cardiovascular risk factor disqualifying women was a CAC score $>50$ AU, which represented $3.7 \%$ of women qualified by phone screen and $14.5 \%$ of disqualified women (Table 1).

The average level of education and income were greater in women meeting eligibility criteria compared to those women who were disqualified. Women who were disqualified also were more likely to have never married or declined to report marital status than women who were qualified (Table 2). Menopausal symptoms scores were similar between women excluded and those meeting eligibility criteria $(9.0 \pm 5.4, n=257$ and $9.4 \pm 5.4, n=728$, respectively). Women meeting eligibility criteria were younger, had lower LDL cholesterol, and had lower systolic blood pressure than women excluded (Table 3).

CIMT in women subsequently disqualified from KEEPS did not differ significantly from that of women meeting eligibility requirements $[0.725 \pm 0.084 \mathrm{~mm}(n=113)$ and $0.726 \pm 0.90 \mathrm{~mm}(n=718)$, respectively]. Repeat CIMT readings on the same individual performed within 90 days had a coefficient of variation between scan 1 and scan 2 of less than $1 \%(0.84 \pm 0.99 \%$; minimum of $0 \%$ and a maximum of $11 \%$ ).

\section{Comparison of Demographics and Cardiovascular Risk Factors of Women Enrolled into KEEPS with Those in the WHI}

Women qualified for KEEPS represent a similar ethnic mix to women enrolled in the CEE+MPA arm of the WHI (Table 4). However, women who qualified for KEEPS had higher levels of education and more declined to report their income level than women in the WHI (Table 2). The percentage of women who qualified for KEEPS who report partnered/ separated and divorced status is similar to that reported in the WHI with the exception that fewer women who qualified for KEEPS reported a widowed status while more reported never having been married. This finding may reflect the difference of nearly a decade in mean ages of participants between the two studies (Tables 2 and 3). Prior hormone use did not differ between participants in KEEPS and WHI but the incidence and severity of menopausal symptoms were strikingly different, with $67 \%$ of KEEPS-qualified women reporting severe symptoms compared to $61 \%$ of WHI women reporting no symptoms. These differences were also characteristic of women in the 50-59-year grouping of the WHI with the exception of the number of participants that were current hormone users and were higher in the WHI than in women qualified for KEEPS (Table 2).
Table 1 Number of recorded reasons for disqualifications from KEEPS by screening examination(s)

\begin{tabular}{|c|c|}
\hline & Number \\
\hline \multicolumn{2}{|l|}{ History } \\
\hline Depression & 3 \\
\hline Over age $(>59$ year $)$ & 1 \\
\hline LMP $>3$ year & 6 \\
\hline Not menopausal & 19 \\
\hline DES exposure in utero & 3 \\
\hline Uterine ablation/hysterectomy & 6 \\
\hline Cardiovascular disease & 2 \\
\hline Medication or hormone use & 14 \\
\hline Thromboembolic disease & 2 \\
\hline History of cancer & 2 \\
\hline $\mathrm{HIV}+$ & 1 \\
\hline Hypertension & 4 \\
\hline Cerebrovascular disease & 1 \\
\hline Gall bladder disease & 0 \\
\hline Diabetes mellitus & 3 \\
\hline Smoke $>10$ cig/day & 1 \\
\hline Other history & 7 \\
\hline \multicolumn{2}{|l|}{ Laboratory tests } \\
\hline $\mathrm{E} 2>40 \mathrm{pg} / \mathrm{mL}$ & 62 \\
\hline $\mathrm{FSH}<35 \mathrm{ng} / \mathrm{mL}$ & 24 \\
\hline $\mathrm{LDL}>190 \mathrm{mg} / \mathrm{dL}$ & 30 \\
\hline Trig $>400 \mathrm{mg} / \mathrm{dL}$ & 2 \\
\hline Hypothyroid (TSH $>5 \quad \mathrm{~mL} \mathrm{U} / \mathrm{L})$ & 4 \\
\hline Hyperthyroid (TSH $<0.2$, fT4 $>2 \mathrm{~mL} \mathrm{U} / \mathrm{L}$ ) & 3 \\
\hline Other & 15 \\
\hline \multicolumn{2}{|l|}{ Physical examination } \\
\hline Hypertension (150/95) & 4 \\
\hline BMI $>35 \mathrm{~mm}^{2} / \mathrm{kg}$ & 11 \\
\hline Breast mass & 3 \\
\hline Abnormal cardiovascular exam ${ }^{\mathrm{a}}$ & 2 \\
\hline Abnormal pelvic exam & 5 \\
\hline Other PE finding & 4 \\
\hline \multicolumn{2}{|l|}{ Other screening tests } \\
\hline CAC scan score $>50$ AU & 42 \\
\hline CIMT scan abnormal & 0 \\
\hline Transvaginal ultrasound $>5 \mathrm{~mm}$ or abnormal & 31 \\
\hline PAP smear abnormal & 4 \\
\hline BDI score $>17$ (depressed) & 10 \\
\hline MMSE score <23 (demented) & 0 \\
\hline Mammogram abnormal & 6 \\
\hline ECG abnormal $^{\mathrm{a}}$ & 12 \\
\hline Endometrial aspirate abnormal & 4 \\
\hline Other imaging/testing abnormal & 5 \\
\hline
\end{tabular}

$L M P$ last menstrual period, DES diethylstilbestrol, $B M I$ body mass index, E2 17 $\beta$-estradiol, FSH follicle-stimulating hormone, $L D L$ lowdensity lipoprotein, Trig triglycerides, $C A C$ coronary arterial calcium, $A U$ Agatston units, CIMT carotid intima-media thickness, $B D I$ Beck Depression Inventory, MMSE minimental state examination, ECG electrocardiogram

${ }^{\text {a }}$ Evidence of myocardial infarction, angina, or congestive heart failure 
Table 2 Demographic characteristics of women screened and qualified for KEEPS compared to those enrolled in the WHI

\begin{tabular}{|c|c|c|c|c|c|c|}
\hline & \multicolumn{4}{|c|}{ KEEPS } & \multicolumn{2}{|l|}{ WHI $(\mathrm{CEE}+\mathrm{MPA})^{\mathrm{a}}$} \\
\hline & \multicolumn{2}{|c|}{ Excluded } & \multicolumn{2}{|c|}{ Qualified } & \multirow{2}{*}{$\begin{array}{l}\text { All average age } 63(N=16,608) \\
\%\end{array}$} & \multirow{2}{*}{$\begin{array}{l}50-59 \text { years }(N=5,522) \\
\%\end{array}$} \\
\hline & $N$ & $\%$ & $N$ & $\%$ & & \\
\hline \multicolumn{7}{|l|}{ Education } \\
\hline Grade school & 18 & 0.5 & 3 & 0.4 & 2.3 & 2.8 \\
\hline Some high school & 35 & 0.9 & 3 & 0.4 & 4.5 & 3.9 \\
\hline High school or GED & 166 & 4.4 & 52 & 7.1 & 19.5 & $16.5^{*}$ \\
\hline Some college/vocational & 416 & 11.1 & 131 & 18.0 & 38.9 & $39.1 *$ \\
\hline College graduate or higher & 1030 & 27.4 & 483 & 66.3 & 34.9 & $37.7 *$ \\
\hline Not answered & 2091 & 55.7 & 56 & 7.7 & ND & ND \\
\hline \multicolumn{7}{|l|}{ Income $^{\mathrm{b}}$} \\
\hline$<\$ 10,000$ & 48 & 1.3 & 5 & 0.7 & 5.5 & 6.5 \\
\hline$\$ 10$ to $<\$ 20,000$ & 85 & 2.3 & 10 & 1.4 & 15.0 & 10.2 \\
\hline$\$ 20$ to $<\$(35) 40,000$ & 122 & 3.2 & 47 & 6.5 & 27.5 & 21.8 \\
\hline$\$(35) 40$ to $\$(50)<60,000$ & 177 & 4.7 & 77 & 10.6 & 21.2 & 20.6 \\
\hline$\$(50) 60$ to $\$(75)<100,000$ & 255 & 6.8 & 101 & 13.9 & 17.7 & 21.5 \\
\hline$\geq \$(75) 100,000$ & 266 & 7.1 & 122 & 16.8 & 13.2 & 19.4 \\
\hline Not answered & 2803 & 74.6 & 366 & 50.3 & ND & ND \\
\hline \multicolumn{7}{|l|}{ Marital status } \\
\hline Married/partnered & 926 & 24.7 & 479 & 65.8 & 60.1 & 63.6 \\
\hline Separated/divorced & 368 & 9.8 & 134 & 18.4 & 16.8 & 23.6 \\
\hline Widowed & 60 & 1.6 & 19 & 2.6 & $19.0^{*}$ & 7.5 \\
\hline Never married & 946 & 25.2 & 83 & 11.4 & 4.1 & $5.2^{*}$ \\
\hline Not answered & 1454 & 38.7 & 13 & 1.8 & ND & ND \\
\hline \multicolumn{7}{|l|}{ Smoking status } \\
\hline Never smokers & ND & ND & 580 & 78.9 & 49.8 & $46.8^{*}$ \\
\hline \multicolumn{7}{|l|}{ MHT use } \\
\hline Never & & & & 78.7 & 73.4 & 70.5 \\
\hline Past & & & & 19.3 & 19.9 & 17.2 \\
\hline Current & & & & 1.9 & 7.7 & $12.3 *$ \\
\hline \multicolumn{7}{|l|}{ Menopausal symptoms } \\
\hline None & 8 & 3.1 & 27 & 3.7 & 61.4 & $42.0 *$ \\
\hline Mild & 76 & 29.6 & 203 & 27.9 & 26.2 & 35.6 \\
\hline Moderate to severe & 173 & 67.3 & 498 & 68.4 & 12.4 & $22.4 *$ \\
\hline
\end{tabular}

$N D$ not determined or reported

${ }^{*} P<0.0001$ (significantly different by chi-square test from KEEPS qualified participants)

${ }^{a}$ Data derived from Annals of Epidemiology 13:S78-S86, 2003 [85]

${ }^{\mathrm{b}}$ Income for the WHI are reported as values in parentheses

A major modifiable CVD risk factor, smoking, was also about $50 \%$ less in qualified KEEPS participants than women of the WHI. All other conventional cardiovascular risk factors comprising the Framingham Risk Score including systolic blood pressure, total cholesterol, and HDL-C were significantly different between women meeting eligibility for KEEPS and those in the WHI (Table 3). The same was true of CVD risk factors not included in the Framingham score such as BMI and fasting triglycerides and glucose, reflecting a reduced 10-year CVD risk for women in KEEPS compared to those in the WHI.

\section{Conclusions and Future Directions}

KEEPS is an example of a study that leveraged characteristics of populations in observational and epidemiological studies and incorporated design elements from basic 
Table 3 Comparison of conventional cardiovascular risk factors of participants in KEEPS with those of WHI participants randomized to CEE+MPA

\begin{tabular}{|c|c|c|c|c|c|}
\hline & \multicolumn{4}{|c|}{ KEEPS } & \multirow{3}{*}{$\begin{array}{l}\text { WHI (CEE+MPA })^{\mathrm{a}} \\
\overline{\text { Mean } \pm \text { SD }}\end{array}$} \\
\hline & \multicolumn{2}{|c|}{ Excluded } & \multicolumn{2}{|c|}{ Qualified } & \\
\hline & $N$ & Mean \pm SD & $N$ & Mean \pm SD & \\
\hline Age & 2,208 & $52.4 \pm 3.5$ & 728 & $52.7 \pm 2.6 * * *$ & $63.3^{*}$ \\
\hline BMI $\left(\mathrm{kg} / \mathrm{m}^{2}\right)$ & 235 & $26.7 \pm 4.6$ & 722 & $26.2 \pm 4.3$ & $28.5 \pm 5.4^{*}$ \\
\hline Systolic BP (mm Hg) & 241 & $122.5 \pm 19.0$ & 722 & $118.6 \pm 15.1 * * *$ & $127.0 \pm 7.1^{*}$ \\
\hline Total cholesterol (mg/dL) & 237 & $220 \pm 44$ & 728 & $215 \pm 29$ & $222 \pm 7 *$ \\
\hline LDL cholesterol (mg/dL) & 236 & $134 \pm 37$ & 728 & $129 \pm 29 * *$ & $135 \pm 33 *$ \\
\hline HDL cholesterol (mg/dL) & 240 & $64 \pm 18$ & 728 & $65 \pm 18$ & $55 \pm 14^{*}$ \\
\hline Triglycerides (mg/dL) & 240 & $94 \pm 53$ & 728 & $90 \pm 50$ & $131 \pm 59 *$ \\
\hline Fasting glucose (mg/dL) & 250 & $88.9 \pm 13.3$ & 728 & $89.1 \pm 9.9$ & $98.4 \pm 19.0 *$ \\
\hline
\end{tabular}

$\overline{{ }^{a}}$ Data derived from Annals of Epidemiology 13:S78-S86, 2003 [85]; for WHI-N=16,608 for age, BMI, and systolic BP, $n=1319$ for all other parameters

$B M I$ body mass index, $B P$ blood pressure

${ }^{*} P<0.01$ (statistical significance from qualified KEEPS participants); ${ }^{* *} P<0.05$ (statistical significance from women excluded from KEEPS);

$* * * P<0.01$ (statistical significance from women excluded from KEEPS)

science studies into its trial design. Thus, women who qualified for KEEPS are younger, healthier, reported more menopausal symptoms, and have fewer cardiovascular risk factors than women in the WHI. Therefore, women in KEEPS more closely match the demographics of women in observational studies. Although observational studies have been criticized for reflecting a "healthy user bias" [72], KEEPS is randomized and blinded so outcomes will not be biased by participant group assignment. Also, KEEPS is more representative of the typical clinical experience, i.e., women who are relatively healthy but who are experiencing menopausal symptoms and who seek MHT around the time of their menopausal transition.

One potential limitation of KEEPS is that the majority of participants are Caucasian and results may not be applicable to diverse ethnic populations. However, as medicine moves toward a pharmacogenomic approach to treatment choice, personal definition of ethnicity may not be as relevant as a genotypic definition. Alternatively, KEEPS may help to define the subset of women for whom MHT may provide the most favorable benefit/risk ratio. Furthermore, because a large percentage of women in KEEPS are never smokers and are otherwise at lower risk of CVD, as was the case in the Estrogen for Prevention of Atherosclerosis Trial [44], KEEPS results should more accurately reflect actions of MHT on arteries less confounded by preexisting atherosclerosis as was the case in the WHI. It might also be expected that as KEEPS proceeds, various biochemical markers and soluble cytokines known to be affected by estrogenic treatments will show less variability among participants because fewer participants are current smokers than in other studies. Smoking is well recognized as a risk factor for CVD and many of the components of tobacco smoke (particulate matter, nicotine, carbon dioxide, oxygen-derived free radicals, and other chemicals) negatively impact the same biochemical pathways affected by estrogen $[5,63,83,96]$.
Table 4 Comparison of race/ethnicity of KEEPS participants with that of participants in WHI

Representation of race/ethnicity as a percentage of entire cohort $N D$ not determined or reported

${ }^{a}$ Data derived from Annals of Epidemiology 13:S78-S86, 2003 [85]

\begin{tabular}{lcll}
\hline \multirow{2}{*}{ Ethnicity } & KEEPS cohort & \multicolumn{2}{l}{$\mathrm{WHI}^{\mathrm{a}}$} \\
\cline { 3 - 4 } & & CEE+MPA all & CEE+MPA 50-59years \\
\hline Hispanic or Latino & 7.3 & 5.3 & 8.9 \\
Caucasian not Hispanic & 70.5 & 84.0 & 77.0 \\
African American alone & 7.6 & 6.8 & 9.7 \\
American Indian and Alaskan Native & 0.3 & 0.3 & 0.5 \\
Asian/Native Hawaiian/Pacific Islander & 2.6 & 2.2 & 2.4 \\
Other race or combination & 1.0 & $\mathrm{ND}$ & $\mathrm{ND}$ \\
Unknown/not reporting & 4.9 & 1.4 & 1.5 \\
\hline
\end{tabular}


In the post-WHI era, recruiting for KEEPS was challenging and the resultant socioeconomic and ethnicity demographics of qualified participants reflect difficulties in recruiting diverse groups of women. Negative reports in the lay media that accompanied the scientific reporting of results from the WHI scared many women away from use of MHT, even those who were highly symptomatic. As in observational studies where women most likely initiated MHT for menopausal symptoms, the majority of women in KEEPS reported moderate to severe menopausal symptoms, unlike the WHI in which symptomatic women were discouraged from participation. It is in women seeking treatment for symptoms that cardiovascular benefit has been reported in observational studies. However, even in the relatively asymptomatic women in the WHI, CAC scores, an outcome of KEEPS, were significantly lower in women between the ages of 50 and 59 years after 7 years of blinded randomized to CEE compared to those receiving placebo [58]. In the future, it will be important to better understand biochemical and physiological differences between women with and without menopausal symptoms and to clarify if even asymptomatic women would receive benefit from MHT for chronic diseases of aging.

An unexpected finding from the KEEPS screening processes was the number (nearly 4\%) of women in this age group, usually considered at low risk for CVD that had to be excluded because of significant CAC, even in the absence of other clinically significant cardiovascular risk factors (i.e., elevated BMI and cholesterol, hypertension, and diabetes). These observations are in agreement with other studies and support the emerging concept that CAC may be a common endpoint of multiple etiologies and may be a sensitive indicator of atherosclerosis in middle-aged humans [20, 21, 26, 54, 94]. As KEEPS continues, new information will be gained regarding how MHT affects progression of $\mathrm{CAC}$ and if the progression is related to conventional risk factors or new biomarkers.

KEEPS will provide the first direct comparison of effects of long-term use of oral versus transdermal MHT on atherosclerosis in women. Such information is essential in order for women to select treatments which best suit their needs and lifestyle.

A major difference between KEEPS and studies in experimental animals is that KEEPS participants underwent natural menopause and not a surgical one. However, there are now established animal models of ovarian failure which should provide useful information about the similarities in vascular actions of estrogen between types of menopause [4, 45]. Furthermore, data are emerging from observational studies of women postovariectomy suggesting that MHT reduces overall mortality and maintains cardiovascular health and neurological function [3, 25, 29, 48, 51, 57, 67-70]. Prospective randomized trials are needed in this group of women to validate the effectiveness of MHT for women independent of the type of menopause [57]. In addition, more information is needed about the type, dose, and duration of progestogen therapies to reduce risk of uterine cancer but still provide cardiovascular benefit [13]. Basic science studies of the combined and pulsed use of progestogens and vascular function are scarce [2, 55, 61, 93].

KEEPS has the advantage of being able to incorporate mechanistic data from basic science studies which were not available at the time of the design of the WHI. Therefore, ancillary studies to the parent KEEPS protocol are ongoing to examine new biomarkers of disease progression and thrombotic risk [49, 50], genetic characterization of estrogen receptors relative to response to MHT and outcomes of KEEPS, measures of endothelial function, and bone health which should provide prospective data to complement data obtained from the WHI and Study of Women Across the Nation [18, 56, 78-81, 90].

Finally, there are lessons to be learned from these experiences of basic scientists and clinical investigators involved in the study of cardiovascular actions of estrogen. First, observational and epidemiological studies are hypothesis generating and do not establish cause and effect. Second, design of prospective clinical studies to test these hypotheses should mimic, as closely as possible, the study population and treatment circumstances of the observational studies. The design should also take into account data from experimental animals in which the basic information on drug action was obtained without confounding variables. Separate studies may be needed to account for such confounding variables (i.e., environmental pollutants, obesity, preexisting conditions like diabetes). Third, the design should not compromise integrity of primary outcomes for unrelated secondary outcomes. Fourth, advancements in understanding the basic mechanisms of action of sex steroids was possible in the environment of sustained funding by National Institutes of Health which attracted the best scientists to tackle difficult questions. And finally, collaboration among interdisciplinary teams will facilitate translation of information from basic science to design of clinical trials and ultimately improve the evidence upon which to base clinical practice. These lessons may be considered obvious and common sense, but are often overlooked.

The KEEPS is an example of a study that has incorporated these lessons. KEEPS has matched its sample population to that of observational studies, controlled for confounding variables such as smoking and pre-clinical vascular disease, and will evaluate a mode of treatment delivery similar to what has been used in the majority of basic science studies. Noninvasive measures of vascular health as outcomes also will allow for analysis of disease progression and help to support a paradigm shift in evaluating primary prevention [7]. Taking advantage of the latest technological advances in imaging, diagnostics, and testing, KEEPS will provide 
valuable information for women making decisions about MHT and their health as they age [41]. The KEEPS cohort, stored serum/plasma, and other data are valuable resources. However, additional support from funding agencies will be required in order to leverage these resources to address new questions generated by KEEPS and to translate new discoveries from basic science to further investigations of this defined cohort.

Acknowledgments KEEPS would not be possible without funding by grants from the Aurora Foundation to the Kronos Longevity Research Institute, NIH HL90639 to VMM, 1 UL1 RR0241501, and the Mayo Foundation; dedicated volunteers participating in this study; and collaborators and coworkers at each study center who include:

Albert Einstein College of Medicine: Ruth Freeman, Hussein Amin, Lubna Pal

Brigham and Women's Hospital/Harvard Medical School: Maria Bueche, Marie Gerhard- Herman, Kate Kalan, Jan Lieson, Kathryn M. Rexrode, Frank Rybicki

Columbia College of Physicians and Surgeons: Luz Sanabria, Maria Soto, Michelle P. Warren, Ralf C. Zimmerman

Kronos Longevity Research Institute: Mary Dunn

Mayo Clinic: Philip A. Araoz, Rebecca Beck, Dalene Bott-Kitslaar, Sharon L. Mulvagh, Teresa G. Zais

University of California, Los Angeles, CAC Reading Center: Chris

Dailing, Yanlin Gao, Angel Solano

University of California, San Francisco: Nancy Jancar, Grechen

Good; Statistical Reading Center: Lisa Palermo

University of Southern California, Atherosclerosis Research Unit: Yanjie Li

University of Utah School of Medicine: M. Nazeem Nanjee, Paul N. Hopkins, Kirtly Jones, Timothy Beals, Stacey Larrinaga-Shum

VA Puget Sound Health Care System and University of Washington School of Medicine: Pamela Asberry, SueAnn Brickle, Colleen Carney, Molly Carr, Monica Kletke, Lynna C. Smith

Yale University, School of Medicine: Kathryn Czarkowski, Linda MacDonald, Mary Jane Minkin, Lubna Pal, Diane Wall, Erin Wolff.

Open Access This article is distributed under the terms of the Creative Commons Attribution Noncommercial License which permits any noncommercial use, distribution, and reproduction in any medium, provided the original author(s) and source are credited.

\section{References}

1. Adams, M. R., Clarkson, T. B., Kaplan, J. R., \& Koritnik, D. R. (1989). Experimental evidence in monkeys for beneficial effects of estrogen on coronary artery atherosclerosis. Transplantation Proceedings, 21, 3662-3664.

2. Adams, M. R., Kaplan, J. R., Manuck, S. B., Koritnik, D. R., Parks, J. S., Wolfe, M. S., et al. (1990). Inhibition of coronary artery atherosclerosis by $17-\beta$-estradiol in ovariectomized

\footnotetext{
${ }^{1}$ It is from the National Center for Research Resources (NCRR), a component of the National Institutes of Health (NIH), and the NIH Roadmap for Medical Research. Contents of this paper are solely the responsibility of the authors and do not necessarily represent the official view of NCRR or NIH. Information on NCRR is available at http:/www.ncrr.nih.gov/. Information on Reengineering the Clinical Research Enterprise can be obtained from http://nihroadmap.nih.gov.
}

monkeys. Lack of an effect of added progesterone. Arteriosclerosis, 10(6), 1051-1057.

3. Allison, M. A., Manson, J. E., Langer, R. D., Carr, J. J., Rossouw, J. E., Pettinger, M. B., et al. (2008). Oophorectomy, hormone therapy, and subclinical coronary artery disease in women with hysterectomy: the Women's Health Initiative Coronary Artery Calcium Study. Menopause, 15(4), 639-647.

4. Appt, S. E., Kaplan, J. R., Clarkson, T. B., Cline, J. M., Christian, P. J., \& Hoyer, P. B. (2008). Destruction of primordial ovarian follicles in adult cynomolgus macaques after exposrue to 4vinylcyclohexene diepoxide: A nonhuman primate model of the menopausal transition. Fertility \& Sterility, 86(4 suppl), 1210-1216.

5. Benowitz, N. L., Kuyt, F., \& Jacob, P. (1984). Influence of nicotine on cardiovascular and hormonal effects of cigarette smoking. Clinical Pharmacology and Therapeutics, 36(1), 74-81.

6. Bergkvist, L., Adami, H. O., Persson, I., Hoover, R., \& Schairer, C. (1989). The risk of breast cancer after estrogen and estrogenprogestin replacement. $N$ Engl J Med, 321(5), 293-297.

7. Blankenhorn, D. H., \& Hodis, H. N. (1994). Duff Memorial Lecture: Arterial imaging and atherosclerosis reversal. Arteriosclerosis and Thrombosis, 14, 177-192.

8. Budoff, M. J., Chen, G. P.-W., Hunter, C. J., Takasu, J., Agrawal, N., Sorochinsky, B., et al. (2005). Effects of hormone replacement on progression of coronary calcium as measured by electron beam tomography. Journal of Women's Health, 14, 410-417.

9. Bush, T. L., Barrett-Connor, E., Cowan, L. D., Criqui, M. H., Wallace, R. B., Suchindran, C. M., et al. (1987). Cardiovascular mortality and noncontraceptive use of estrogen in women: Results from the Lipid Research Clinics Program Follow-up Study. Circulation, 75, 1102-1109.

10. Bush, T. L., Cowan, L. D., Barrett-Connor, E., Criqui, M. H., Karon, J. M., Wallace, R. B., et al. (1983). Estrogen use and allcause mortality. Preliminary results from the Lipid Research Clinics Program Follow-up Study. Journal of the American Medical Association, 249(7), 903-906.

11. Byington, R. P., Furberg, C. D., Herrington, D. M., Herd, J. A., Hunninghake, D. B., Lowery, M., et al. (2002). Effect of estrogen plus progestin on progression of carotid atherosclerosis in postmenopausal women with heart disease: HERS B-mode substudy. Arteriosclerosis, Thrombosis, and Vascular Biology, 22, 1692-1697.

12. Cauley, J. A., Robbins, J., Chen, Z., Cummings, S. R., Jackson, R. D., LaCroix, A. Z., et al. (2003). Effects of estrogen plus progestin on risk of fracture and bone mineral density: the Women's Health Initiative randomized trial. Journal of the American Medical Association, 290 (13), 1729-1738.

13. Cho, M. M. H., Hodis, H. N., Mack, W. J., Roy, S., Paulson, R. J., Li, Y., et al. (2008). Medroxyprogesterone acetate and progesterone, used short-term, do not adversely affect forearm reactive hyperemia in postmenopausal women on estradiol therapy. International Journal of Endocrinology and Metabolism, 2, 63-69.

14. Clarkson, T. B., Kaplan, J. R., Wagner, J. D., Williams, J. K., \& Adams, M. R. (2002). Lessons from animal models. In P. S. Douglas (Ed.), Cardiovascular health and disease in women (pp. 231-256). Philadelphia: Saunders.

15. Clarkson, T. B., Prichard, R. W., Morgan, T. M., Petrick, G. S., \& Klein, K. P. (1994). Remodeling of coronary arteries in human and nonhuman primates. Journal of the American Medical Association, 271(4), 289-294.

16. Col, N. F., Eckman, M. H., Karas, R. H., Pauker, S. G., Goldberg, R. J., Ross, E. M., et al. (1997). Patient-specific decisions about hormone replacement therapy in postmenopausal women. Journal of the American Medical Association, 277(14), 1140-1147.

17. Colditz, G. A., Hankinson, S. E., Hunter, D. J., Willett, W. C., Manson, J. E., Stampfer, M. J., et al. (1995). The use of estrogens and progestins and the risk of breast cancer in postmenopausal women. New England Journal of Medicine, 332(24), 1589-1593. 
18. Crandall, C. J., Crawford, S. L., \& Gold, E. B. (2006). Vasomotor symptom prevalence is associated with polymorphisms in sex steroid-metabolizing enzymes and receptors. American Journal of Medicine, 119(9 Suppl 1), S52-60.

19. Darling, G. M., Johns, J. A., McCloud, P. I., \& Davis, S. R. (1997). Estrogen and progestin compared with simvastatin for hypercholesterolemia in postmenopausal women. New England Journal of Medicine, 337(9), 595-601.

20. Desai, M. Y., Nasir, K., Braunstein, J. B., Rumberger, J. A., Post, W. S., Budoff, M. J., et al. (2004). Underlying risk factors incrementally add to the standard risk estimate in detecting subclinical atherosclerosis in low- and intermediate-risk middle-aged asymptomatic individuals. American Heart Journal, 148(5), 871-877.

21. Detrano, R., Guerci, A. D., Carr, J. J., Bild, D. E., Burke, G., Folsom, A. R., et al. (2008). Coronary calcium as a predictor of coronary events in four racial or ethnic groups. New England Journal of Medicine, 358(13), 1336-1345.

22. Eilertsen, A. L., Hoibraaten, E., Os, I., Andersen, T. O., Sandvik, L., $\&$ Sandset, P. M. (2005). The effects of oral and transdermal hormone replacement therapy on C-reactive protein levels and other inflammatory markers in women with high risk of thrombosis. Maturitas, 52(2), 111-118.

23. Ettinger, B., Black, D. M., Mitlak, B. H., Knickerbocker, R. K., Nickelsen, T., Genant, H. K., et al. (1999). Reduction of vertebral fracture risk in postmenopausal women with osteoporosis treated with raloxifene: Results from a 3-year randomized clinical trial. Multiple Outcomes of Raloxifene Evaluation (MORE) Investigators. Journal of the American Medical Association, 282(7), 637-645.

24. Ettinger, B., Friedman, G. D., Bush, T., \& Quesenberry, C. P., Jr. (1996). Reduced mortality associated with long-term postmenopausal estrogen therapy. Obstetrician \& Gynaecologist, 87(1), 6-12.

25. Farish, E., Fletcher, C. D., Hart, D. M., \& Smith, M. L. (1990). Effects of bilateral oophorectomy on lipoprotein metabolism. British Journal of Obstetrics and Gynaecology, 97, 78-82.

26. Folsom, A. R., Kronmal, R. A., Detrano, R. C., O'Leary, D. H., Bild, D. E., Bluemke, D. A., et al. (2008). Coronary artery calcification compared with carotid intima-media thickness in the prediction of cardiovascular disease incidence: the Multi-Ethnic Study of Atherosclerosis (MESA). Archives of Internal Medicine, 168(12), 1333-1339.

27. Folsom, A. R., Mink, P. J., Sellers, T. A., Hong, C. P., Zheng, W., \& Potter, J. D. (1995). Hormonal replacement therapy and morbidity and mortality in a prospective study of postmenopausal women. American Journal of Public Health, 85(8 Pt 1), 1128-1132.

28. Futterman, L. G., \& Lemberg, L. (2001). Lp(a) lipoprotein-an independent risk factor for coronary heart disease after menopause. American Journal of Critical Care, 10(1), 63-67.

29. Grady, D., Rubin, S. M., Petitti, D. B., Fox, C. S., Black, D., Ettinger, B., et al. (1992). Hormone therapy to prevent disease and prolong life in postmenopausal women. Annals of Internal Medicine, 117, 1016-1032.

30. Greenland, P., Bonow, R. O., Brundage, B. H., Budoff, M. J., Eisenberg, M. J., Grundy, S. M., et al. (2007). ACCF/AHA 2007 clinical expert consensus document on coronary artery calcium scoring by computed tomography in global cardiovascular risk assessment and in evaluation of patients with chest pain: a report of the American College of Cardiology Foundation Clinical Expert Consensus Task Force (ACCF/AHA Writing Committee to Update the 2000 Expert Consensus Document on Electron Beam Computed Tomography) developed in collaboration with the Society of Atherosclerosis Imaging and Prevention and the Society of Cardiovascular Computed Tomography. Journal of the American College of Cardiology, 49(3), 378-402.

31. Grodstein, F., Clarkson, T. B., \& Manson, J. E. (2003). Understanding the divergent data on postmenopausal hormone therapy. New England Journal of Medicine, 348, 645-650.
32. Grodstein, F., Manson, J. E., Colditz, G. A., Willett, W. C., Speizer, F. E., \& Stampfer, M. J. (2000). A prospective, observational study of postmenopausal hormone therapy and primary prevention of cardiovascular disease. Annals of Internal Medicine, 133, 933-941.

33. Grodstein, F., Manson, J. E., \& Stampfer, M. J. (2006). Hormone therapy and coronary heart disease: The role of time since menopause and age at hormone initiation. Journal of Women's Health, 15, 35-44.

34. Grodstein, F., Stampfer, M. J., Colditz, G. A., Willett, W. C., Manson, J. E., Joffe, M., et al. (1997). Postmenopausal hormone therapy and mortality. New England Journal of Medicine, 336, 1769-1775.

35. The Women's Health Initiative Study Group. (1998). Design of the women's health initiative clinical trial and observational study. Controlled Clinical Trials, 19, 61-109.

36. Harman, S. M., Brinton, E. A., Cedars, M., Lobo, R., Manson, J. E., Merriam, G. R., et al. (2005). KEEPS: The Kronos Early Estrogen Prevention Study. Climacteric, 8, 3-12.

37. Henderson, B. E., Paganini-Hill, A., \& Ross, R. K. (1991). Decreased mortality in users of estrogen replacement therapy. Archives of Internal Medicine, 151(1), 75-78.

38. Herrington, D. M., Reboussin, D. M., Brosnihan, K. B., Sharp, P. C., Shumaker, S. A., Snyder, T. E., et al. (2000). Effects of estrogen replacement on the progression of coronary-artery atherosclerosis. $N$ Engl J Med, 343, 522-529.

39. Herrington, D. M., Werbel, B. L., Riley, W. A., Pusser, B. E., \& Morgan, T. M. (1999). Individual and combined effects of estrogen/ progestin therapy and lovastatin on lipids and flow-mediated vasodilation in postmenopausal women with coronary artery disease. Journal of the American College of Cardiology, 33(7), 2030-2037.

40. Hodis, H. N., \& Mack, W. J. (2002). Atherosclerosis imaging methods: assessing cardiovascular disease and evaluating the role of estrogen in the prevention of atherosclerosis. American Journal of Cardiology, 889, 19E-27E.

41. Hodis, H. N., \& Mack, W. J. (2008). Postmenopausal hormone therapy and cardiovascular disease in perspective. Clinical Obstetrics and Gynecology, 51, 564-580.

42. Hodis, H. N., Mack, W. J., Azen, S. P., Lobo, R. A., Shoupe, D., Mahrer, P. R., et al. (2003a). Hormone therapy and the progression of coronary-artery atherosclerosis in postmenopausal women. New England Journal of Medicine, 349, 535-545.

43. Hodis, H. N., Mack, W. J., \& Lobo, R. (2003b). What is the cardioprotective role of hormone replacement therapy? Current Atherosclerosis Reports, 5, 56-66.

44. Hodis, H. N., Mack, W. J., Lobo, R. A., Shoupe, D., Sevanian, A., Mahrer, P. R., et al. (2001). Estrogen in the prevention of atherosclerosis. A randomized, double-blind, placebo-controlled trial. Annals of Internal Medicine, 135, 939-953.

45. Hoyer, P. B., \& Sipes, I. G. (2007). Development of an animal model for ovotoxicity using 4-vinylcyclohexene: A case study. Developmental and Reproductive toxicology, 80, 113-125.

46. Hsia, J., Langer, R. D., Manson, J. E., Kuller, L., Johnson, K. C., Hendrix, S. L., et al. (2006). Conjugated equine estrogens and coronary heart disease. Archives of Internal Medicine, 166, 357-365.

47. Hulley, S., Grady, D., Bush, T., Furberg, C., Herrington, D., Riggs, B., et al. (1998). Randomized trial of estrogen plus progestin for secondary prevention of coronary heart disease in postmenopausal women. Heart and Estrogen/progestin Replacement Study (HERS) Research Group. Journal of the American Medical Association, 280(7), 605-613.

48. Jacoby, V. L., Grady, D., \& Sawaya, G. F. (2009). Oophorectomy as a risk factor for coronary heart disease. American Journal of Obstetrics and Gynecology, 200, 140.e141-140.e149.

49. Jayachandran, M., Litwiller, R. D., Owen, W. G., Heit, J. A., Behrenbeck, T. R., Mulvagh, S. L., et al. (2008). Characterization 
of blood borne microparticles as markers of premature coronary calcification in recently menopausal women. American Journal of Physiology, Heart and Circulatory Physiology, 295, 931-938.

50. Jayachandran, M., Litwiller, R. D., Owen, W. G., \& Miller, V. M. (2009). Circulating microparticles and endogenous estrogen in newly menopausal women. Climacteric, 12, 1-8.

51. Kalantaridou, S., Naka, K., Bechlioulis, A., Makrigiannakis, A., Michalis, L., \& Chrousos, P. (2006). Premature ovarian failure, endothelial dysfunction and estrogen-progestogen replacement. TRENDS in Endocrinology and Metabolism, 17(3), 101-109.

52. Karas, R. H., Schulten, H., Pare, G., Aronovitz, M. J., Ohlsson, C., Gustafsson, J. A., et al. (2001). Effects of estrogen on the vascular injury response in estrogen receptor alpha, beta (double) knockout mice. Circulation Research, 89, 534-539.

53. Karim, R., Mack, W. J., Lobo, R. A., Hwang, J., Liu, C. R., Liu, C. H., et al. (2005). Determinants of the effect of estrogen on the progression of subclinical atherosclerosis: Estrogen in the Prevention of Atherosclerosis Trial. Menopause, 12, 366-373.

54. Lakoski, S. G., Greenland, P., Wong, N. D., Schreiner, P. J., Herrington, D. M., Kronmal, R. A., et al. (2007). Coronary artery calcium scores and risk for cardiovascular events in women classified as "low risk" based on Framingham Risk Score: The Multi-Ethnic Study of Atherosclerosis (MESA). Archives of Internal Medicine, 167(22), 2437-2442.

55. Levine, R. L., Chen, S.-J., Durand, J., Chen, Y.-F., \& Oparil, S. (1994). Medroxyprogesterone attenuates estrogen-mediated inhibition of neointima formation after balloon injury of the rat carotid artery. Circulation, 94, 2221-2227.

56. Lo, J. C., Zhao, X., Scuteri, A., Brockwell, S., \& Sowers, M. R. (2006). The association of genetic polymorphisms in sex hormone biosynthesis and action with insulin sensitivity and diabetes mellitus in women at midlife. American Journal of Medicine, 119(9 Suppl 1), S69-78.

57. Mack, W. J., Slater, C. C., Xiang, M., Shoupe, D., Lobo, R. A., \& Hodis, H. N. (2004). Elevated subclinical atherosclerosis associated with oophorectomy is related to time since menopause rather than type of menopause. Fertility \& Sterility, 82(2), 391-397.

58. Manson, J., Allison, M., Rossouw, J. E., Carr, J., Langer, R., Hsia, J., et al. (2007). Estrogen therapy and coronary-artery calcification. $N$ Engl J Med, 356(25), 2591-2602.

59. Manson, J. E., Hsia, J., Johnson, K. C., Rossouw, J. E., Assaf, A. R., Lasser, N. L., et al. (2003). Estrogen plus progestin and the risk of coronary heart disease. New England Journal of Medicine, 349, 523-534.

60. Mendelsohn, M. E., \& Karas, R. H. (2005). Molecular and cellular basis of cardiovascular gender differences. Science, 308, 1583-1587.

61. Miller, V. M., \& Vanhoutte, P. M. (1991). Progesterone and modulation of endothelium-dependent responses in canine coronary arteries. American Journal of Physiology, 261, R1022R1027.

62. Murphy, S. L. (2000). Deaths: Final data for 1998. National Vital Statistics Reports, 48(11), 1-105.

63. Ockene, I. S., \& Miller, N. H. (1997). Cigarette smoking, cardiovascular disease, and stroke: A statement for healthcare professionals from the American Heart Association. American Heart Association Task Force on Risk Reduction. Circulation, 96, 3243-3247.

64. Raggi, P., Cooil, B., Shaw, L. J., Aboulhson, J., Takasu, J., Budoff, M., et al. (2003). Progression of coronary calcium on serial electron beam tomographic scanning is greater in patients with future myocardial infarction. American Journal of Cardiology, 92, 827-829.

65. Randell, K. M., Honkanen, R. J., Kroger, H., \& Saarikoski, S. (2002). Does hormone-replacement therapy prevent fractures in early postmenopausal women? Journal of Bone and Mineral Research, 17(3), 528-533.
66. Rexrode, K. M., \& Manson, J. E. (2007). Are some types of hormone therapy safer than others? Lessons from the Estrogen and Thromboembolism Risk study. Circulation, 115(7), 820-822.

67. Rocca, W., Grossardt, B., Andrade, M., Malkasian, G., \& Melton, L. I. (2006). Survival patterns after oophorectomy in premenopausal women: a population-based cohort study. Lancet Oncology, 7, 821-828.

68. Rocca, W. A., Bower, J. H., Maraganore, D. M., Ahlskog, J. E., Grossardt, B. R., de Andrade, M., et al. (2007a). Increased risk of parkinsonism in women who underwent oophorectomy before menopause. Neurology, 70, 200-209.

69. Rocca, W. A., Bower, J. H., Maraganore, D. M., Ahlskog, J. E., Grossardt, B. R., de Andrade, M., et al. (2007b). Increased risk of cognitive impairment or dementia in women who underwent oophorectomy before menopause. Neurology, 69(11), 1074-1083.

70. Rocca, W. A., Grossardt, B. R., Geda, Y. E., Gostout, B. S., Bower, J. H., Maraganore, D. M., et al. (2008). Long-term risk of depressive and anxiety symptoms after early bilateral oophorectomy. Menopause, 15(6), 1050-1059.

71. Rossouw, J. E., Anderson, G. L., Prentice, R. L., LaCroix, A. Z., Kooperberg, C., Stefanick, M. L., et al. (2002). Risks and benefits of estrogen plus progestin in healthy postmenopausal women: Principal results from the Women's Health Initiative randomized controlled trial. Journal of the American Medical Association, 288 (3), 321-333

72. Rossouw, J. E., Finnegan, L. P., Harlan, W. R., Pinn, V. W., Clifford, C., \& McGowan, J. A. (1995). The evolution of the Women's Health Initiative: Perspective from the NIH. Journal of the American Medical Women's Association, 50, 50-55.

73. Rumberger, J. A., Schwartz, R. S., Sheedy, P. F., III, Edwards, W. D., \& Fitzpatrick, L. A. (1994). Coronary calcification and pathologic stenosis: An ROC analysis to predict atherosclerotic severity and the influence of gender using ultrafast computed tomography. American Journal of Cardiology, 74, 1169-1173.

74. Scarabin, P. Y., Alhenc-Gelas, M., Plu-Bureau, G., Taisne, P., Agher, R., \& Aiach, M. (1997). Effects of oral and transdermal estrogen/progesterone regimens on blood coagulation and fibrinolysis in postmenopausal women: A randomized controlled trial. Arteriosclerosis, Thrombosis, and Vascular Biology, 17, 3071-3078.

75. Scarabin, P. Y., Oger, E., \& Plu-Bureau, G. (2003). Differential association of oral and transdermal oestrogen-replacement therapy with venous thromboembolism risk. Lancet, 362, 428-432.

76. Schairer, C., Lubin, J., Troisi, R., Sturgeon, S., Brinton, L., \& Hoover, R. (2000). Menopausal estrogen and estrogen-progestin replacement therapy and breast cancer risk. Journal of the American Medical Association, 283, 485-491.

77. Slater, C. C., Hodis, H. N., Mack, W. J., Shoupe, D., Paulson, R. J., \& Stanczyk, F. Z. (2001). Markedly elevated levels of estrone sulfate after long-term oral, but not transdermal administration of estradiol in postmenopausal women. Menopause, 8, 200-2003.

78. Sowers, M. R., Jannausch, M. L., McConnell, D. S., Kardia, S. R., \& Randolph, J. F., Jr. (2006a). Endogenous estradiol and its association with estrogen receptor gene polymorphisms. American Journal of Medicine, 119 (9 Suppl 1), S16-22.

79. Sowers, M. R., Symons, J. P., Jannausch, M. L., Chu, J., \& Kardia, S. R. (2006b). Sex steroid hormone polymorphisms, highdensity lipoprotein cholesterol, and apolipoprotein A-1 from the Study of Women's Health Across the Nation (SWAN). American Journal of Medicine, 119 (9 Suppl 1), S61-68.

80. Sowers, M. R., Wilson, A. L., Kardia, S. R., Chu, J., \& McConnell, D. S. (2006c). CYP1A1 and CYP1B1 polymorphisms and their association with estradiol and estrogen metabolites in women who are premenopausal and perimenopausal. American Journal of Medicine, $119(9$ Suppl 1), S44-S51.

81. Sowers, M. R., Wilson, A. L., Karvonen-Gutierrez, C. A., \& Kardia, S. R. (2006d). Sex steroid hormone pathway genes and 
health-related measures in women of 4 races/ethnicities: the Study of Women's Health Across the Nation (SWAN). American Journal of Medicine, 119(9 Suppl 1), S103-110.

82. Spencer, C., Crook, D., Ross, D., Cooper, A., Whitehead, M., \& Stevenson, J. (1999). A randomised comparison of the effects of oral versus transdermal 17beta-oestradiol, each combined with sequential oral norethisterone acetate, on serum lipoprotein levels. British Journal of Obstetrics and Gynaecology, 106(9), 948-953.

83. Spieker, L. E., Flammer, A. J., \& Luscher, T. F. (2006). The vascular endothelium in hypertension. Handbook of Experimental Pharmacology, 176(Pt 2), 249-283.

84. Stampfer, M. J., \& Colditz, G. A. (1991). Estrogen replacement therapy and coronary heart disease: A quantitative assessment of the epidemiologic evidence. Preventive Medicine, 20, 47-63.

85. Stefanick, M., Cochrane, B., Hsia, J., Barad, D., Liu, J., \& Johnson, S. (2003). The women's health initiative postmenopausal hormone trials: Overview and baseline characteristics of participants. AEP, 13, S78-S86.

86. Steiner, A., Hodis, H. N., Lobo, R. A., Shoupe, D., Xiang, M., \& Mack, W. J. (2005). Postmenopausal oral estrogen therapy and blood pressure in normotensive and hypertensive subjects: the Estrogen in the Prevention of Atherosclerosis Trial. Menopause, $12,728-733$.

87. Sudhir, K., Chou, T. M., Chatterjee, K., Smith, E. P., Williams, T. C., Kane, J. P., et al. (1997a). Premature coronary artery disease associated with a disruptive mutation in the estrogen receptor gene in a man. Circulation, 96, 3774-3777.

88. Sudhir, K., Chou, T. M., Mullen, W. L., Hausmann, D., Collins, P., Yock, P. G., et al. (1995). Mechanisms of estrogen-induced vasodilatation: In vivo studies in canine coronary conductance and resistance arteries. Journal of the American College of Cardiology, 26, 807-814.

89. Sudhir, K., Esler, M. D., Jennings, G. L., \& Komesaroff, P. A. (1997b). Estrogen supplementation decreases norepinephrineinduced vasoconstriction and total body norepinephrine spillover in perimenopausal women. Hypertension, 30, 1538-1543.

90. Sutton-Tyrrell, K., Wildman, R. P., Matthews, K. A., Chae, C., Lasley, B. L., Brockwell, S., et al. (2005). Sex-hormone-binding globulin and the free androgen index are related to cardiovascular risk factors in multiethnic premenopausal and perimenopausal women enrolled in the Study of Women Across the Nation (SWAN). Circulation, 111(10), 1242-1249.

91. The Writing Group for the PEPI Trial. (1995). Effects of estrogen or estrogen/progestin regimens on heart disease risk factors in postmenopausal women: The Postmenopausal Estrogen/Progestin Interventions (PEPI) Trial. Journal of the American Medical Association, 273, 199-208.

92. Waddell, T. K., Rajkumar, C., Cameron, J. D., Jennings, G. L., Dart, A. M., \& Kingwell, B. A. (1999). Withdrawal of hormonal therapy for 4 weeks decreases arterial compliance in postmenopausal women. Journal of Hypertension, 17(3), 413-418.

93. Wagner, J. D., Clarkson, T. B., St. Clair, R. W., Schwenke, D. C., Shively, C. A., \& Adams, M. R. (1991). Estrogen and progesterone replacement therapy reduces low density lipoprotein accumulation in the coronary arteries of surgically postmenopausal cynomolgus monkeys. Journal of Clinical Investigation, 88(6), 1995-2002.

94. Weintraub, W. S., \& Diamond, G. A. (2008). Predicting cardiovascular events with coronary calcium scoring. New England Journal of Medicine, 358(13), 1394-1396.

95. White, C. R., Shelton, J., Chen, S.-J., Darley-Usmar, V., Allen, L., Nabors, C., et al. (1998). Estrogen restores endothelial cell function in an experimental model of vascular injury. Circulation, 96, 1624-1630.

96. Wilson, P. W., Garrison, R. J., \& Castelli, W. P. (1985). Postmenopausal estrogen use, cigarette smoking, and cardiovascular morbidity in women over 50. The Framingham Study. [see comment]. New England Journal of Medicine, 313(17), 1038-1043.

97. Wolf, P. H., Madans, J. H., Finucane, F. F., Higgins, M., \& Kleinman, J. C. (1991). Reduction of cardiovascular diseaserelated mortality among postmenopausal women who use hormones: Evidence from a national cohort. American Journal of Obstetrics and Gynecology, 164, 489-494.

98. Zhu, Y., Bian, Z., Lu, P., Karas, R. H., Bao, L., Cox, D., et al. (2002). Abnormal vascular function and hypertension in mice deficient in estrogen receptor beta. Science, 295(5554), 505-508. 